\title{
Objetos Educacionais Digitais e sua integração aos livros didáticos de Matemática
}

Digital Learning Objects and their integration on textbooks

\author{
Gabriela Prampolim ${ }^{1}$ \\ Rúbia Barcelos Amaral-Schio²
}

\section{Resumo}

O presente texto é fruto de uma pesquisa qualitativa que abordou os Objetos Educacionais Digitais (OED) presentes em uma coleção de Matemática dos Anos Finais do Ensino Fundamental, aprovada pelo Programa Nacional do Livro Didático, responsável por avaliar e distribuir os livros às escolas públicas. A análise foca questões relacionadas ao ambiente matemático e ao nível de interação, salientando o papel do professor no processo de integração das tecnologias na sala de aula. Os resultados mostram que os OED têm uma abordagem interativa, criando um espaço propício à exploração do conteúdo, de forma lúdica. No que tange aos ambientes de aprendizagem, trazem poucas opções relacionadas à realidade, considerando, em sua maioria, questões da Matemática Pura. Em termos de melhoria, aponta-se a necessidade de efetiva integração com os livros didáticos, visto que os OED são referenciados nas edições estudadas, sem nenhuma conexão com o seu conteúdo, como uma "etiqueta" colada na página. Ademais, cabe ressaltar a falta de preocupação com a acessibilidade, pois os OED não têm recursos para usuários com deficiências. Tais questões, ainda que focadas em uma coleção específica, podem iluminar a análise de outros recursos a serem utilizados nas aulas de Matemática.

Palavras-chave: Educação Matemática. Interatividade. OED. PNLD. Tecnologias digitais.

\section{Introdução}

O Programa Nacional do Livro Didático (PNLD) é responsável pela avaliação e distribuição das obras a todos os alunos das escolas públicas brasileiras. A partir de 2014, assume a importância e o desafio de integrar a tecnologia na sala de aula (BRASIL, 2012), onde faz dos conteúdos multimídias, denominados oficialmente como Objetos Educacionais Digitais (OED), parte complementar dos livros impressos. Para Nesbit et al. (2004, p.2):

\footnotetext{
1 Graduanda do Curso de Matemática, UNESP - Rio Claro, gabriela.prampolim@hotmail.com

2 Professora Livre-Docente do Departamento de Educação Matemática, UNESP - Rio Claro, rubiaba@rc.unesp.br.
} 
Objetos de aprendizagem ${ }^{3}$ são recursos de informação ou software interativo usado na aprendizagem on-line. Uma única imagem, uma página de texto, uma simulação interativa ou um curso inteiro podem ser exemplos de objetos de aprendizagem.

Este artigo se contextualiza na análise crítica dos OED presentes nas coleções aprovadas pelo Edital 2014, que se refere aos anos finais do Ensino Fundamental e é fruto da pesquisa "A Geometria nos livros didáticos e a integração das tecnologias digitais", financiada pela Fapesp ${ }^{4}$. Das dez coleções, apenas três possuíam OED. A análise de uma dessas coleções foi realizada por Ribeiro e Amaral (2016) e o presente texto o complementa na medida em que traz resultados da investigação de outra coleção: Vontade de Saber, da Editora FTD (SOUZA; PATARO, 2012). Análises de diferentes recursos tecnológicos podem contribuir para iluminar outras práticas de integração das mídias na sala de aula de Matemática.

\section{Notas teóricas}

Para a análise dos OED, consideramos aspectos como ambientes de aprendizagem, interatividade e as possibilidades e limitações de uso pelos alunos (aqui incluída a qualidade do conteúdo, acessibilidade, entre outros).

Inicialmente refletimos acerca dos ambientes de aprendizagem apresentados por Skovsmose (2011), que são divididos em seis categorias: (1) dominado por exercícios da Matemática Pura; (2) envolve questões do tipo "o que acontece se...", geralmente explorando números e figuras geométricas; (3) exercícios contextualizados em uma semirrealidade, uma situação artificial; (4) uso de uma semirrealidade como um recurso para a produção de atividades investigativas; (5) exercícios baseados em um contexto real; (6) exploração de dados reais, o que sugere diferentes significados para as atividades para cada um dos envolvidos, indo além da criação de conceitos matemáticos. As categorias (1), (3) e (5) estão relacionadas com a aprendizagem através de exercícios,

3 Neste texto "Objetos Educacionais Digitais" e "Objetos de aprendizagem" são considerados recursos de natureza semelhante.

${ }^{4}$ Auxílio Regular. Processo 2013/22975-3. 
enquanto as categorias (2), (4) e (6) estão associam-se com cenário para investigação. Além disso, as categorias (1) e (2) referem-se à Matemática Pura; (3) e (4) possuem referência à semirrealidade; e (5) e (6) abordam contextos reais, como sintetiza a tabela abaixo:

Tabela 1 - Ambiente de Aprendizagem por Skovsmose (2011)

\begin{tabular}{|c|c|c|}
\hline & Exercícios & Cenário para Investigação \\
\hline Referências à matemática pura & $(1)$ & $(2)$ \\
\hline Referências à semirrealidade & $(3)$ & $(4)$ \\
\hline Referências à realidade & $(5)$ & $(6)$ \\
\hline
\end{tabular}

Fonte: Skovsmose (2011)

Em relação aos níveis de interatividade, nos embasamos na classificação de Lévy (1999), que considera os seguintes aspectos: Personalização, em que há a possibilidade de se apropriar da imagem recebida; Reciprocidade, onde é disponibilizado um dispositivo que permite a comunicação um-um ou todos-todos; Virtualidade, onde se enfatiza a mensagem em tempo real; Implicação, no qual o espectador controla um representante de si; e Telepresença, na qual o espectador interage de sua casa em um programa ao vivo.

Assumimos, ainda, o método LORI de Nesbit et al. (2004), que avalia: Qualidade do Conteúdo, com relação à sua veracidade, precisão, apresentação balanceada das ideias e nível de detalhes apropriados; Alinhamento de Metas de Aprendizagem, que aborda o alinhamento entre os objetivos de aprendizagem, as atividades e avaliações e características do aluno; Feedback e Adaptação, que avalia se o conteúdo é adaptável ou se é possível um feedback pelo aluno durante ou após o uso; Motivação, relacionado com a capacidade de motivar e interessar os alunos; Design, corresponde ao design de informações visuais e auditivas para melhor aprendizado e um processamento mental eficiente; Usabilidade, que se relaciona com a facilidade de navegação, previsibilidade da interface do usuário e qualidade dos recursos de ajuda da interface; Acessibilidade, abordando o design dos controles e formatos de apresentação para também atingir alunos com necessidades especiais; Reutilização, em que se tem a capacidade de utilizar o objeto em diferentes contextos de aprendizagem e 
com alunos de diferentes origens; e Conformidade com as Normas, que aborda a adesão às normas e especificações internacionais. Para cada um destes é utilizada uma classificação em níveis, de 0 a 5 estrelas, sendo 5 estrelas a maior avaliação possível que o tópico possa receber.

Da classificação de Lévy (1999), não levaremos em conta a Telepresença, por relacionar-se a programa televisivo. Já no âmbito do método LORI de Nesbit et al. (2004), o último tópico não foi considerado, uma vez que nosso foco é a análise dos OED dentro do âmbito nacional, considerando as normas do PNLD. Como os OED aqui discutidos já foram avaliados e aprovados pelo PNLD, não vamos ampliar este aspecto apontado pelo autor.

Quanto ao aspecto da Acessibilidade de Nesbit et al. (2004), verificaremos se o OED poderia ser utilizado para os alunos abarcados pelo Atendimento Especial Especializado (AEE), que "é o conjunto de atividades e recursos de acessibilidade e pedagógicos organizados institucional e continuamente para atender exclusivamente alunos com algum tipo de necessidade especial, no contraturno escolar" (ARANHA, 2015). Os grupos de estudantes englobados pelo AEE são aqueles com deficiência (neste incluem-se alunos cegos, surdos, que apresentam dislexia ou déficit de atenção, etc.), com transtornos globais do desenvolvimento (como pessoas altistas, com síndrome de Asperger, entre outros) e com altas habilidades/superdotação (aqueles que apresentam potencial elevado nas áreas do conhecimento humano).

Cabe observar que a presente pesquisa complementa os resultados previamente compartilhados no que tange a análise de OED, que foram apresentados nacional e internacionalmente, e são frutos de trabalhos de colaboração entre pesquisadores e orientandos de Pós-Graduação, assumindo diferentes lentes teóricas para o embasar a análise (AMARAL, 2014; RIBEIRO; GODOY, 2014; AMARAL, 2016; AMARAL; RIBEIRO, 2018). Ainda com foco nos OED, um estudo foi realizado com alunos bolsistas do PIBID - Programa Institucional de Bolsa de Iniciação à Docência. Como esses alunos vão às escolas públicas para suas atividades no Programa, além de um estudo teórico sobre 
temas pertinentes à análise dos OED, foi sugerida sua aplicação na escola vinculada ao PIBID, tomando como observação a opinião dos alunos (GUTZLAF; SANTOS; DECO, 2014; FERREIRA; POLETTI; SANTANA, 2014). Outras análises foram realizadas em parceria com alunas da Licenciatura em Matemática, considerando Mayer (2009) como suporte teórico (MELITO; GOLDINHO; AMARAL, 2014; MOURA; AMARAL, 2014).

Em especial, destacamos o texto de Ribeiro e Amaral (2016), que considera os OED das coleções aprovadas pelo PNLD 2014. Para a análise, se baseiam em Cannito (2009), que divide os objetos com relação à sua interatividade com o usuário em três níveis: reativo - onde o usuário limita-se a reagir com escolhas predefinidas; coativo - onde já se permite certo controle; e o proativo - em que o usuário pode modificar a estrutura e/ou conteúdo, agindo também como produtor. $\mathrm{O}$ foco do artigo é fazer uma avaliação dos OED contidos em uma das coleções aprovadas e relacioná-los com a apresentação realizada pelo Guia sobre eles. A avaliação realizada pelos autores acerca dos OED é relativa à natureza, tipo, conteúdo explorado e sua relação com o local em que se encontra no livro didático.

Ao longo do artigo os autores ainda afirmam que a componente digital só é válida se trouxer uma novidade ao conteúdo, além do oferecido pelo livro impresso, do contrário ele poderia ser chamado de OENR (Objetos Educacionais com uma Nova Roupagem), que pouco contribui para a melhoria dos processos de ensino e aprendizagem. Após a análise, observaram que a maioria dos OED está mais para um OENR ou são reativos, ou seja, alguns OED configuram-se como uma proposta similar ao que o aluno (e o professor) faria com lápis e papel, sem qualquer diferencial potencializado pela tecnologia, o que Gadanidis e Borba (2008) denominam de "domesticação das mídias".

Por fim, ressaltamos o trabalho de Santos e Amaral (2012), que analisam dois objetos pertencentes a repositórios de iniciativas nacionais, um do BIOE (Banco Internacional de Objetos Educacionais) e outro da CESTA (Coletânea de Entidades de Suporte ao uso de Tecnologia na Aprendizagem), ambos de acesso 
livre e gratuito. Para contextualizar, o artigo explica que os repositórios de OED funcionam "como um sistema de armazenamento digital, onde de qualquer computador com acesso a internet estes recursos podem ser acessados" (SANTOS; AMARAL, 2012, p. 86), tendo como objetivo armazenar e disseminar as produções digitais. Além disso, os autores afirmam que existem diversos repositórios disponíveis na internet, em sua grande maioria vinculados a projetos acadêmicos de instituições de ensino nacionais e internacionais. Após a análise, com o uso da classificação de Nesbit et al. (2004), os autores observam que os objetos podem contribuir significativamente para a melhoria da aprendizagem, sempre deixando claro que não é simples e/ou fácil reconhecer e/ou avaliar a qualidade dos OED.

\section{Aspectos metodológicos}

O presente trabalho busca compartilhar resultados advindos da análise em uma abordagem interpretativa de pesquisa qualitativa. Como afirmam Bogdan e Biklen (1994, p.209), os estudos dessa natureza "devem revelar maior preocupação pelo processo e significado e não pelas suas causas e efeitos". E, nesse sentido, o foco está na análise dos OED de uma das coleções aprovadas pelo PNLD 2014, a coleção Vontade de saber, da Editora FTD (SOUZA; PATARO, 2012), e não em seus resultados ou produtos, o que contempla uma das características centrais da pesquisa qualitativa, segundo Denzin e Lincoln (2000) e Vidich e Lyman (2000).

Para a análise, partimos da tabela abaixo, que foi preenchida para cada um dos oito OED, sendo dois destinados ao $6^{\circ}$ ano, três ao $8^{\circ}$ ano e outros três para ○ $9^{\circ}$ ano. Cabe notar que não há OED oficialmente dedicado para $\circ 7^{\circ}$ ano nessa coleção analisada. No que tange a classificação, observamos que são três jogos, um infográfico, uma hipermídia e três simuladores. 
Tabela 2 - Tabela para Avaliação dos OED

\begin{tabular}{|c|c|}
\hline TÍTULO DO OED & \\
\hline CLASSIFICAÇÃOO & \\
\hline DESCRIÇÃO DO GUIA & \\
\hline DESCRIÇÃO & \\
\hline CONTEÚDO & \\
\hline ANÁLISE EM TÓPICOS & \\
\hline TEXTO DE ANÁLISE & \\
\hline
\end{tabular}

Fonte: Das autoras.

Após essa primeira etapa, os objetos foram analisados à luz de Skovsmose (2011), Nesbit et al. (2004) e Lévy (1999). Os resultados são descritos na próxima seção.

\section{Possibilidades e limitações dos OED}

Nesta seção apresentamos nossa síntese crítica dos OED. Negócios do Oriente, destinado ao $6^{\circ}$ ano, é, segundo o Guia, "uma hipermídia que apresenta um simulador de soroban e um teste com atividades de adição e subtração" (BRASIL, 2013, p.93). Nele é possível abordar as operações de soma e subtração em um contexto de cálculo em um mercado japonês. No entanto, o que se percebe é que esta contextualização não ocorre, ou é muito sutil, ao longo do desenvolvimento das atividades do OED. Tais atividades implicam em solucionar a lista de soma ou subtração de cada nível (Figura 1), onde os níveis se intercalam entre soma e subtração. Conforme o aluno vai avançando, há um aumento do número de algarismos nos números utilizados nos cálculos. 


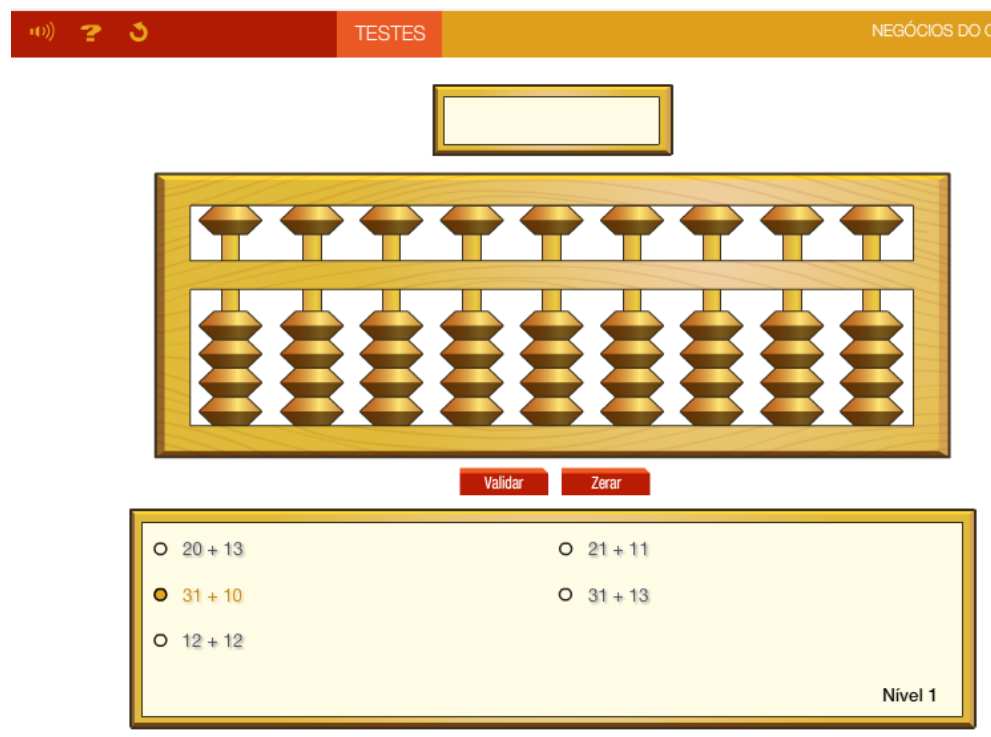

Figura 1: Negócios do Oriente

Fonte: Souza e Pataro (2012)

O OED também precisa de um conhecimento prévio sobre o uso do soroban, especialmente sobre o aspecto da operação em outra base (base cinco), diferente daquela tradicional (base dez) utilizada nas aulas de Matemática, levando o aluno a pensar o papel da base no processo das operações de soma e subtração. Ainda que pareça facilmente substituível pela versão física, o feedback para o usuário a respeito de seu cálculo estar correto, ou não, é muito mais fácil e rápido em sua versão virtual.

Ainda assim, o contexto poderia ser melhor trabalhado ao longo do OED, já que este limitou-se à resolução direta de contas, quando poderia ter um enunciado que trabalharia, além da soma e subtração, a interpretação de problemas matemáticos, fazendo com que o conhecimento matemático pudesse ser visto como um elemento mais palpável já que, tratando-se de um mercado, poderiam envolver enunciados em consonância com o cotidiano do aluno.

Números do Brasil é, segundo o Guia, "um infográfico com dados sobre regiões e estados brasileiros" (BRASIL, 2013, p.93), que é para ser trabalhado no $6^{0}$ ano. Inicialmente é apresentado um mapa com as divisões em regiões e informações sobre o país (Figura 2), tais como: capital, extensão territorial, população, número de médicos por 1000 habitantes, percentual de pessoas 
alfabetizadas a partir de 5 anos de idade, percentual de pessoas com acesso residencial à internet, número de municípios e PIB per capita. Quando o usuário clica em alguma região (Figura 3), as mesmas informações (exceto capital) são apresentadas. $\mathrm{O}$ mesmo se repete com os estados dentro da região previamente selecionada (Figura 4).

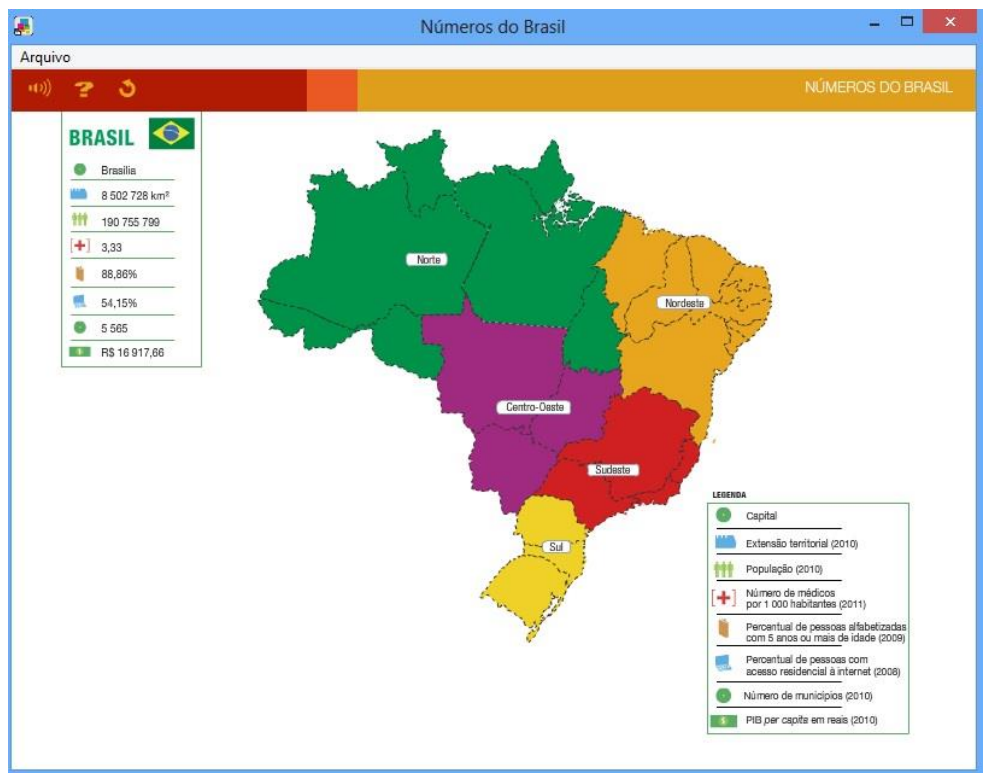

Figura 2: Números do Brasil - País

Fonte: Souza e Pataro (2012)

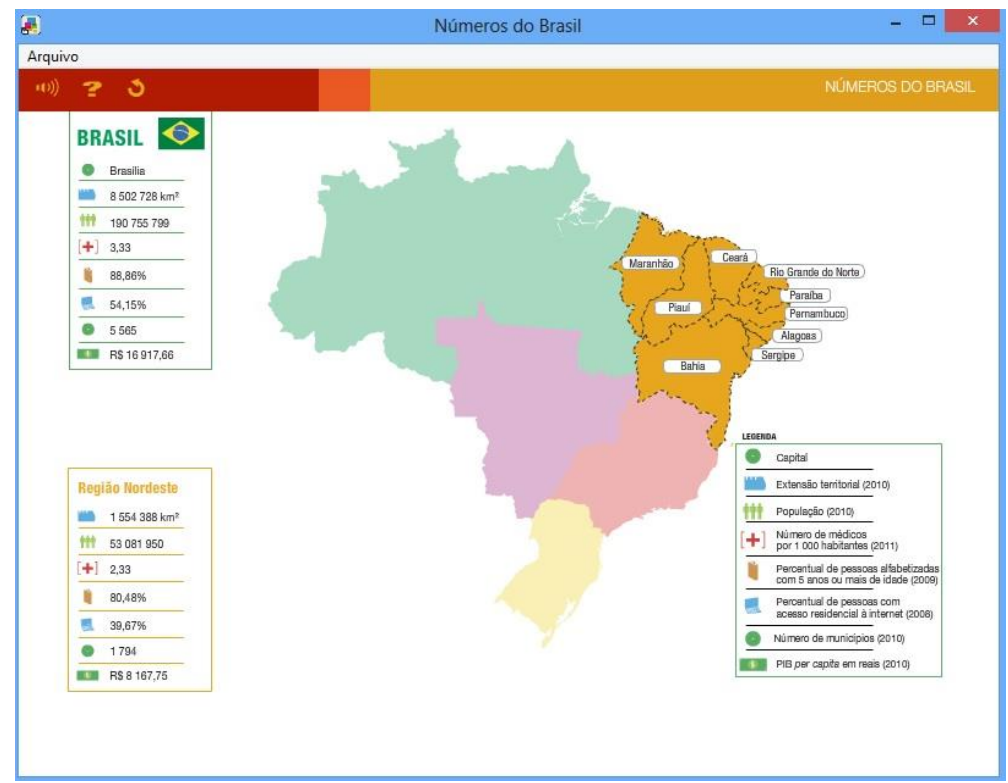

Figura 3: Números do Brasil - Regiões

Fonte: Souza e Pataro (2012) 


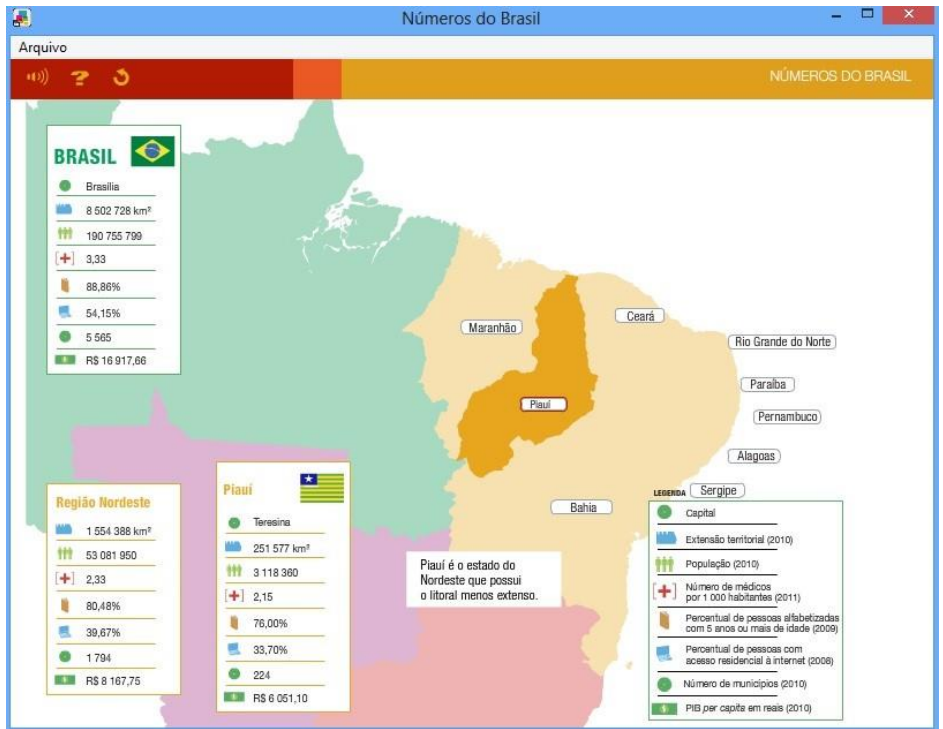

Figura 4: Números do Brasil - Estado Fonte: Souza e Pataro (2012)

O OED é de simples utilização e visualmente atrativo. Também é interessante pelo fato de que ele proporciona ao professor a possibilidade de desenvolver atividades interdisciplinares, por exemplo, dentro de um contexto da Matemática e da Geografia. Pode ser utilizado para abordar unidades de medida, comparação, porcentagem, entre outros, portanto, demanda do professor contextualizá-lo matematicamente.

O simulador Analisando Medidas, destinado ao $8^{\circ}$ ano, apresenta cinco personagens, além de um avatar editável pelo usuário, para se adequar às medidas de idade, massa corporal e altura deste ou as que este desejar inserir (Figura 5). Segundo o Guia, o OED "simula o cálculo da moda, mediana, média, máximo e mínimo de idade, peso e altura de cinco personagens"5 (BRASIL, 2013, p.93). Entre os personagens, o usuário deve escolher no mínimo dois para que, com isto, o simulador realize os cálculos de média, mediana, moda, máximo e mínimo com relação à altura, massa corporal e idade dos personagens previamente selecionados.

${ }^{5}$ Observamos que a única frase do Guia traz uma informação errada sobre o OED, pois para o cálculo da média, e demais análises de medidas, consideram os cinco personagens e o avatar. 


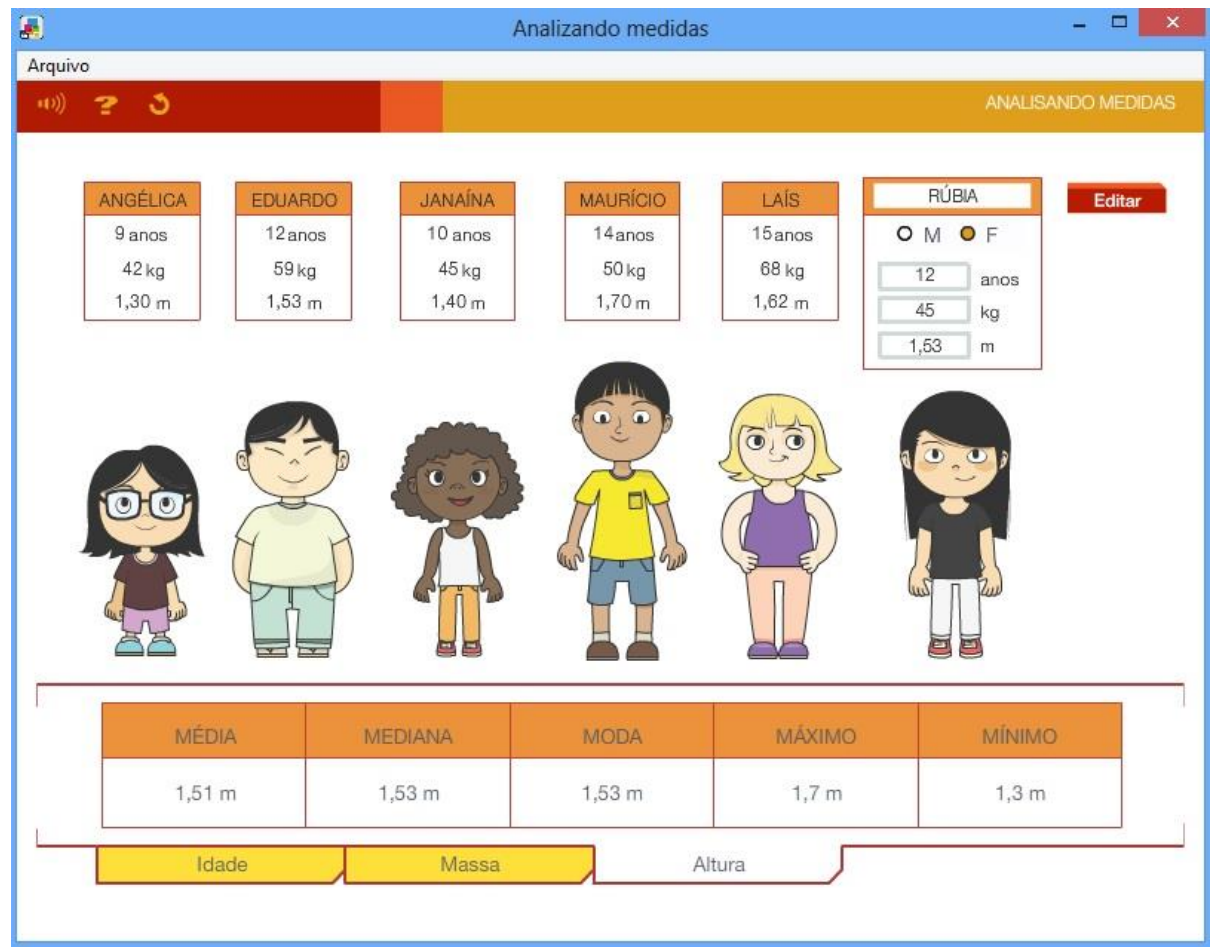

Figura 5: Analisando Medidas

Fonte: Souza e Pataro (2012)

Por ser um simulador, o OED não explica os processos dos cálculos realizados, apenas fornece os resultados. Portanto, é recomendável que o professor organize sua aula considerando as possibilidades de exploração desses conceitos (se vai usar como aplicação do conteúdo, se prefere utilizar para iniciar o conceito, etc.).

Sorteando Bolas é para ser utilizado no $8^{\circ}$ ano e é definido pelo Guia como "um simulador de sorteios de bolas coloridas colocadas em uma dada urna e os resultados são fornecidos em gráficos e tabelas" (BRASIL, 2013, p.93). O OED aborda probabilidade, mais especificamente, combinação e, para isto, oferece ao usuário a possibilidade de escolher uma quantidade (entre 0 e 99 bolas) para cada uma das cinco cores de bolas (vermelha, verde, azul, amarela e alaranjada), após isto, deve-se clicar em "colocar bolas", para que elas sejam inseridas na urna. Em seguida, o usuário decide a quantidade de sorteios a serem realizados com as bolas (1, 5, 10, 50 ou 100 sorteios) e então clica em "sortear", possuindo a opção de parar durante o sorteio. Na sequência o OED apresenta tabela com 
informações sobre "bolas na urna" e "bolas sorteadas", com as quantidades e porcentagens de cada bola com relação ao total. Também é apresentado um gráfico de barras que relaciona ambas pelas cores de bolas, como pode ser visto na Figura 6.

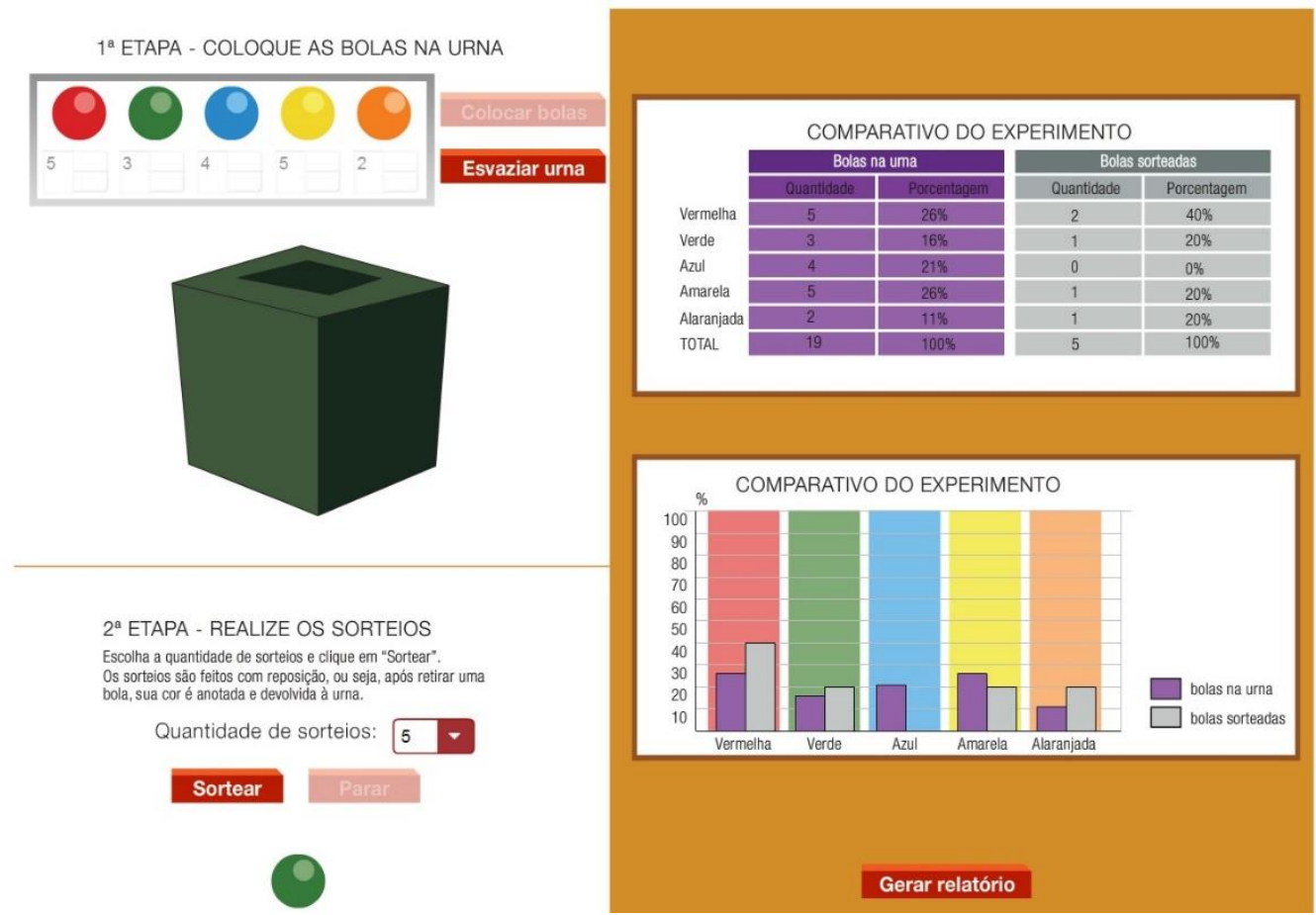

Figura 6: Sorteando Bolas

Fonte: Souza e Pataro (2012)

O OED é simples de ser utilizado e interessante para o ensino de combinação, pois o professor pode usá-lo para introduzir o conteúdo, uma vez que não há a necessidade de um conhecimento prévio do aluno sobre o conceito de probabilidade.

Quadriláteros é um jogo, destinado ao $8^{\circ}$ ano, que, segundo o Guia, "explora, de modo interessante e criativo, propriedades de quadriláteros em uma malha" (BRASIL, 2013, p.93); de fato, o jogo é interessante, visualmente atrativo e facilmente manipulável. $\mathrm{O}$ jogo traz, em sua construção, um tipo de quadrilátero para ser feito na malha apresentada e uma regra: colocar exatamente três estrelas, que estão dispersas nesta malha (Figura 7) dentro do quadrilátero pedido. Os quadriláteros pedidos pelo jogo são: paralelogramos - entre eles 0 
retângulo (não quadrado), o losango (não quadrado) e o quadrado - e trapézios, inicialmente sem nenhum requisito e, posteriormente, trapézio isósceles e trapézio escaleno. Para a construção do quadrilátero solicitado, com três estrelas em seu interior, é preciso ter clareza sobre as propriedades dos quadriláteros. Dessa forma, podemos considerar este um jogo de fixação, que requer uma explicação paralela ou antecipada sobre os quadriláteros, como denominação, definição e diferença entre suas propriedades.

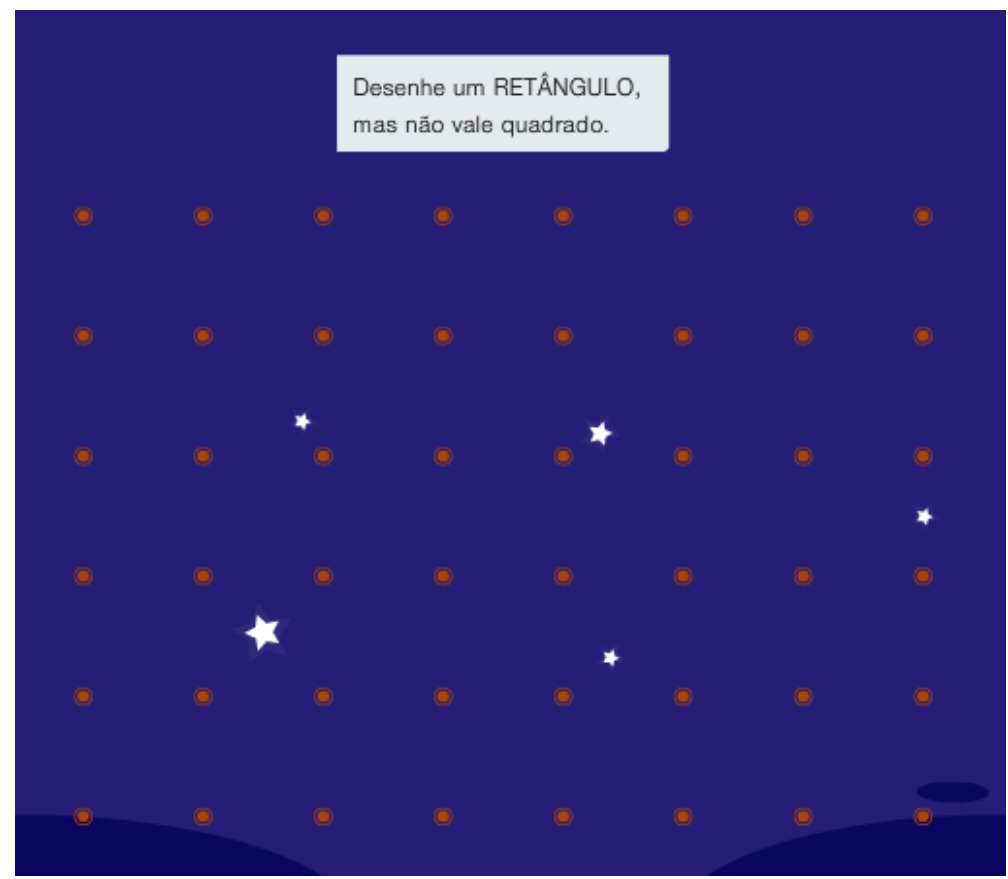

Figura 7: Quadriláteros - Fase 16

Fonte: Souza e Pataro (2012)

O OED Juro Simples e Juro Composto é "um simulador de gráficos sobre aplicações financeiras", segundo o Guia (BRASIL, 2013, p.93), para ser utilizado no 9o ano. Um capital de $R \$ 1000,00$ é fornecido inicialmente e este será aplicado a uma taxa, definida pelo usuário, por um período também determinado pelo usuário (12, 24 ou 36 meses). O cálculo é apresentado em um gráfico, de tempo (meses) por montante $(R \$)$, em duas curvas: uma azul, para juros compostos, e uma vermelha, para juros simples (Figura 8 ). Também é possível visualizar um ponto específico do gráfico, desde que ele esteja exatamente na linha que 
corresponde a algum mês - com isso é possível comparar o montante com relação ao tipo de juros aplicado nele em determinado mês.

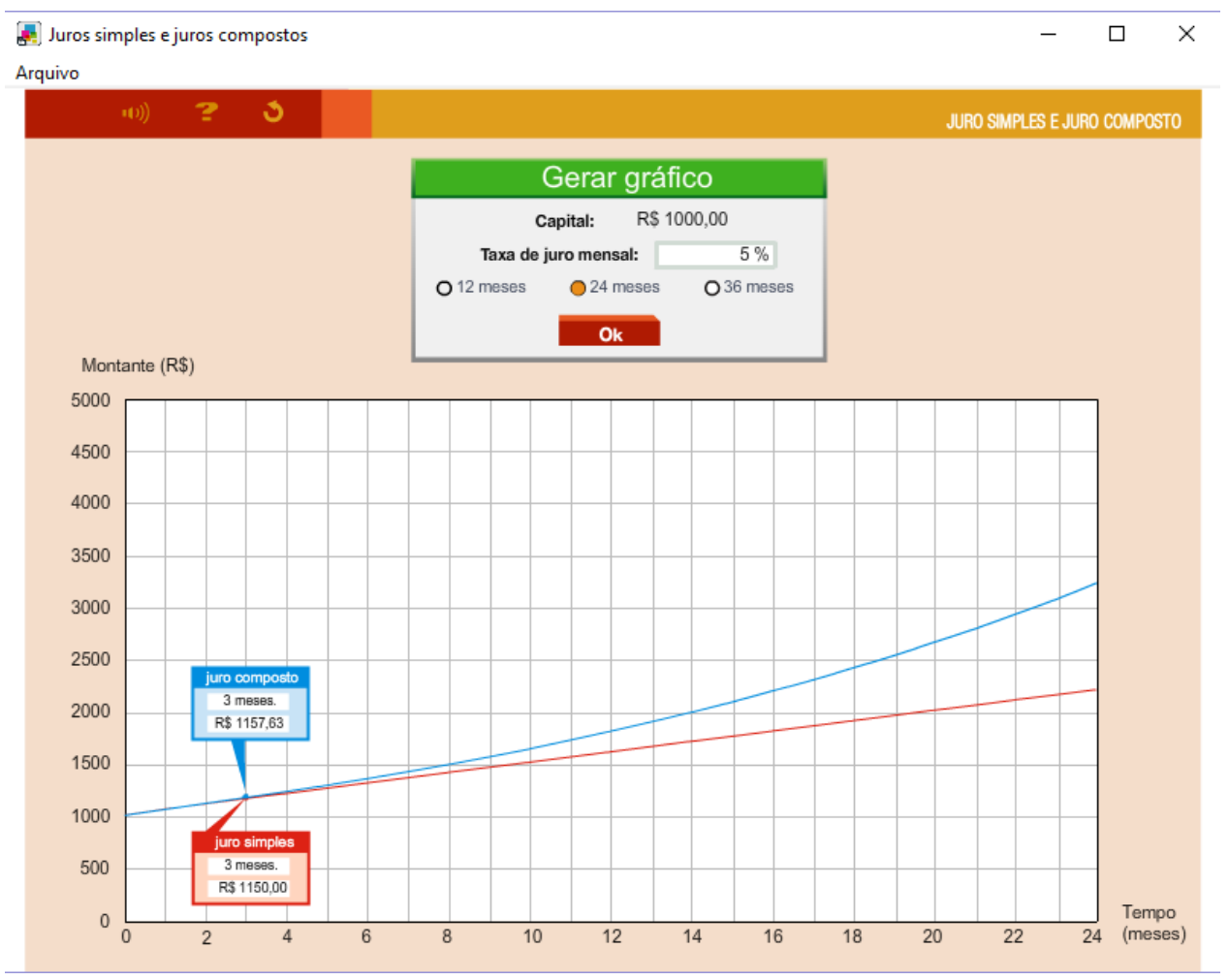

Figura 8: Juro Simples e Juro Composto

Fonte: Souza e Pataro (2012)

Este simulador é um OED propício para inicializar os conceitos de juros simples e compostos. O professor pode criar um contexto adequado, de modo que a partir dos dados e dos gráficos gerados se inicie a discussão das principais diferenças entre os juros simples e composto.

O OED é de fácil manipulação e tem uma construção bem visual, além de possibilitar a realização de diversas experiências, variando a taxa de juros utilizada sobre o mesmo capital, e comparar as curvas formadas, tanto com relação à variação da taxa, quanto ao tipo de juros utilizado (composto ou simples).

O Jogo dos Arcos de Circunferência, igualmente destinado ao 9ำ ano, é descrito pelo Guia como um jogo "que explora o conceito de ângulo e de comprimento de arco" (BRASIL, 2013, p.93) e utiliza-se desses conceitos num 
contexto puramente matemático. O jogo é dividido em duas categorias: iniciante e avançado. Em ambas é solicitado marcar 100 pontos ou mais em 5 tentativas. $\mathrm{Na}$ circunferência são apresentadas três tarjas, duas amarelas, que valem 15 pontos, e uma vermelha, que vale 30 , e move-se um ponteiro para atingir essas targetas, através do valor dado pelo usuário.

A categoria iniciante possui três fases: na primeira fase é necessário apenas digitar o valor do ângulo em graus e escolher sentido horário ou antihorário (Figura 9, à esquerda); a segunda fase parte de uma dada medida de raio da circunferência e pede-se o comprimento do arco (Figura 9, à direita); na terceira e última fase é dada a área da circunferência e pede-se o comprimento do arco correspondente (Figura 10, à esquerda). Nas duas últimas fases, as medidas são dadas em centímetros, e também deve-se escolher o sentido do ponteiro. Já na categoria avançado (Figura 10, à direita), a única diferença é que as tarjas são menores, o que dificulta a pontuação, pois as informações oferecidas ao OED a fim de obter os pontos precisam ser mais precisas.
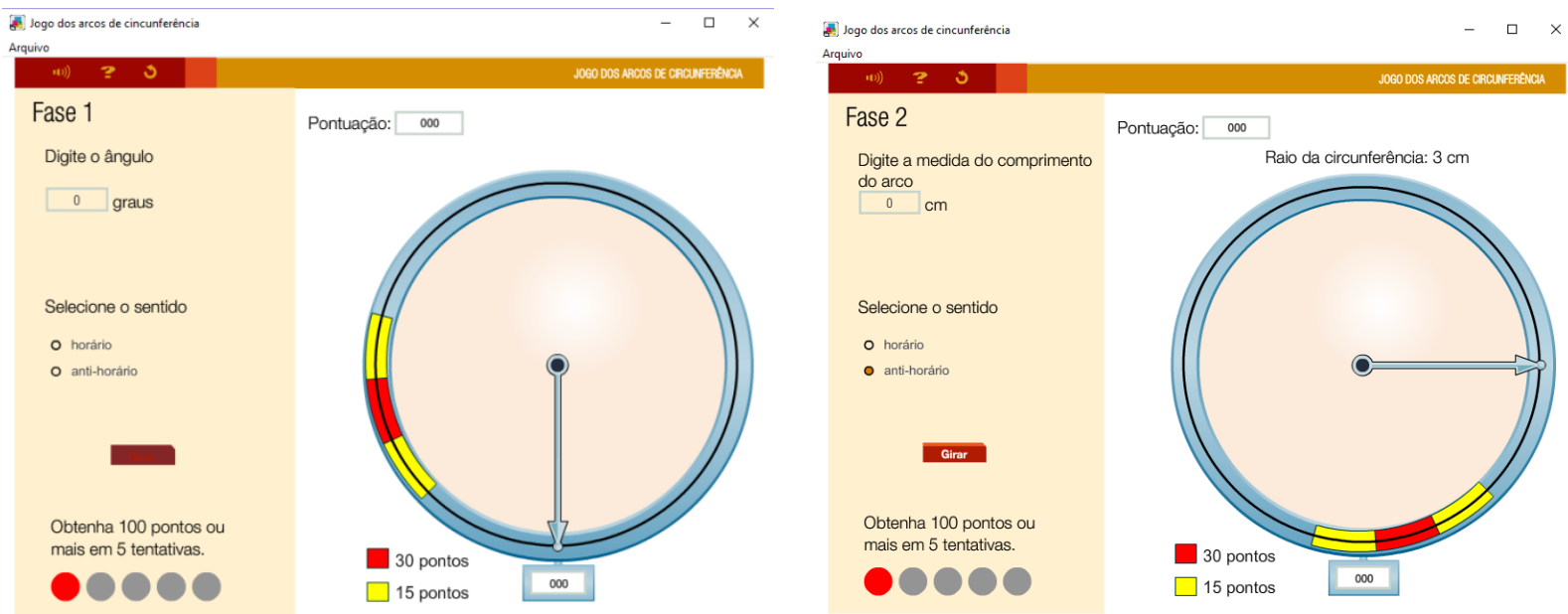

Figura 9: Jogo dos Arcos de Circunferência - Fase 1 (iniciante) e Fase 2 (iniciante) Fonte: Souza e Pataro (2012) 

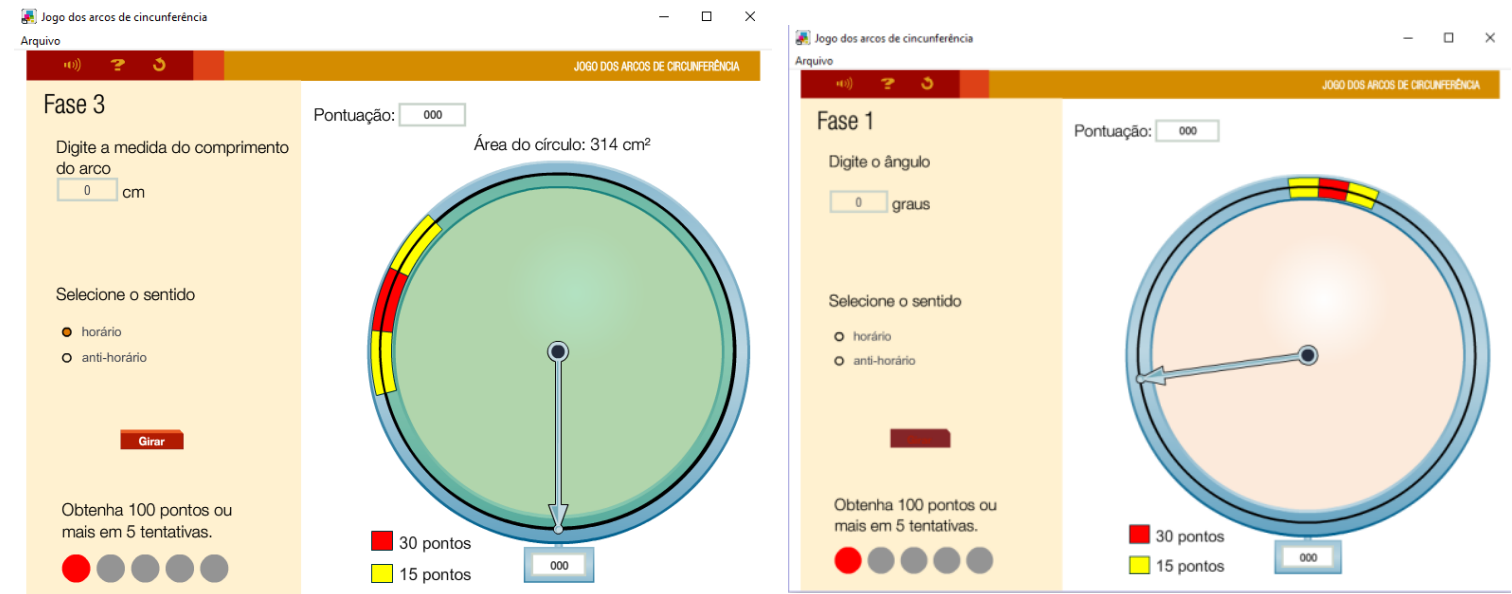

Figura 10: Jogo dos Arcos de Circunferência - Fase 3 (iniciante) e Fase 1 (avançado) Fonte: Souza e Pataro (2012)

O jogo é de fácil manipulação, visualmente agradável e explora o conceito amplamente, mas necessita-se de uma explicação prévia ou paralela sobre o conteúdo relacionado às situações apresentadas no jogo.

O Jogo dos Aquários, desenvolvido para o 9ํano, é descrito pelo Guia como um jogo "sobre o volume de água em dois paralelepípedos, que é atrativo e instigante" (BRASIL, 2013, p.93), utiliza-se de estratégia para, combinando o volume dos sólidos, onde suas medidas são apresentadas em decímetro, e realizando a transferência de líquido, conseguir a quantidade de litros solicitada (Figura 11). Portanto, o OED pode ser visto como um experimento para estudar o conceito de volume, de modo contextualizado. Dessa forma, é adequado para aplicar o conceito de volume e oferecer ao aluno outra situação, mais realista, sobre o conteúdo matemático trabalhado. Ainda que seja visualmente atrativo e de fácil manipulação, o jogo é complexo e isso pode gerar tanto uma desistência como a motivação do aluno quanto à busca pela resolução do desafio, cabendo ao professor ficar atento à forma como propor o uso desse recurso. Seria interessante se o OED possuísse a opção de encher o recipiente apenas pela 
metade ou em alguma outra fração, previamente fixada, tornando a situaçãoproblema mais parecida com a realidade.

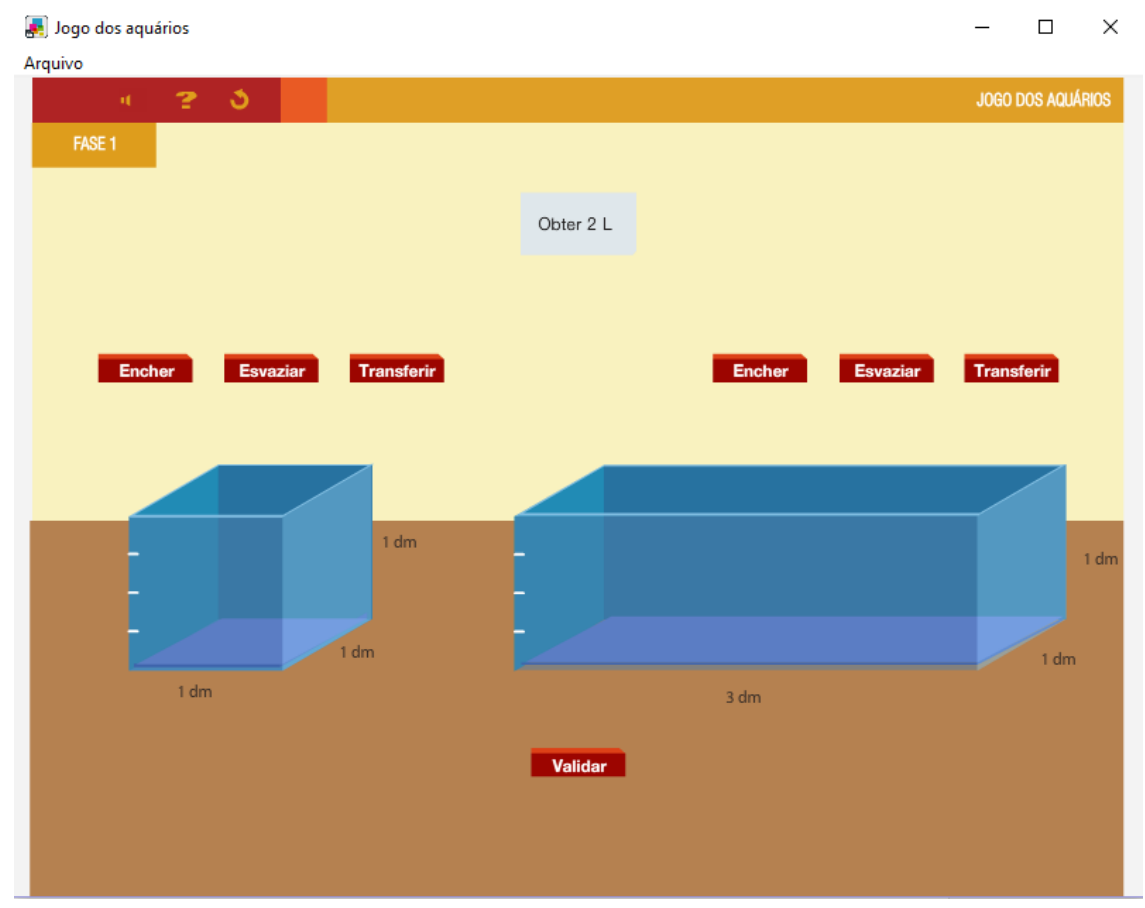

Figura 11: Jogo dos Aquários - Fase 1

Fonte: Souza e Pataro (2012)

À luz da classificação de Skovsmose (2011), tabulamos os OED da seguinte forma:

Tabela 3 - Avaliação por Skovsmose (2011)

\begin{tabular}{|c|c|c|}
\hline & Exercícios & Cenário para Investigação \\
\hline Referências à Matemática Pura & & $\begin{array}{c}\text { Sorteando Bolas } \\
\text { Jogo dos Arcos de } \\
\text { Circunferência } \\
\text { Juros Simples e Juros Composto }\end{array}$ \\
\hline Referências à semirrealidade & $\begin{array}{c}\text { Jogo dos Aquários } \\
\text { Negócios do Oriente }\end{array}$ & $\begin{array}{c}\text { Quadriláteros } \\
\text { Analisando Medidas }\end{array}$ \\
\hline Referências à realidade & & Números do Brasil \\
\hline
\end{tabular}

Fonte: Das autoras

Com relação ao nível de interatividade, por Lévy (1999), em geral, os OED são de Personalização, em que há a possibilidade de apropriação da imagem recebida, ou seja, relacionando com os objetos, é possível apreender os 
conceitos matemáticos utilizados ao longo das atividades, à exceção de Analisando Medidas, que é de Implicação, ou seja, o usuário controla um representante de si, ao colocar seus próprios dados no OED.

No que tange o Método LORI 1.5 de Nesbit et al. (2004), valemo-nos a classificação em estrelas que relacionamos cada OED. Sobre a Qualidade do Conteúdo apresentado nos OED, todos variam entre 4 e 5 estrelas, e enfatizamos que há OED que necessitam que os conteúdos tenham sido estudados previamente à sua utilização, como tem OED que pode ser usado com o objetivo de introduzir o conceito, requerendo que o professor prepare um contexto de investigação pelo aluno, para então levar à sua formalização.

O Alinhamento de Metas de Aprendizagem, que se relaciona com os objetivos de aprendizagem, recebeu entre 2 e 3 estrelas, pois nenhum deles está efetivamente integrado ao livro didático, já que as orientações ao professor, apresentadas nas páginas finais dos livros, sequer citam o OED. Além disso, o fato de que, na página em que o OED está, teoricamente, inserido, não há qualquer menção a ele, com exceção de uma imagem muito simples, apenas com seu título, sem relacionar tal imagem e, em consequência, o próprio OED, com o conteúdo da página em questão. Como mencionam Ribeiro e Amaral (2016), as figuras são como "etiquetas" coladas nos livros, sem qualquer ligação com o texto.

Em relação ao Feedback e à Adaptação, todos receberam zero estrelas, pois não possuem um recurso de avaliação final pelo usuário. No âmbito da Motivação, consideramos que os OED poderiam levar 4 a 5 estrelas, visto que há vários que se constituem em cenários para investigação, levando os alunos a levantar hipóteses, questionar, fazer explorações, envolvendo assim o aluno. Quanto ao Design e à Usabilidade, consideramos pertinente 4 e 5 estrelas pois, em sua maioria, as instruções básicas de uso são apresentadas pelo OED, sem a necessidade de uma intervenção exterior. Obviamente que no caso da utilização dos OED como forma de introduzir o conteúdo demanda uma mediação maior do professor, que apresenta inicialmente um contexto que leva à investigação, bem 
como um momento de fechamento com a formalização. Certamente uma discussão final relacionando os OED e o conteúdo em estudo é pertinente à exploração de qualquer dos OED.

A Acessibilidade, por sua vez, foi ignorada pelos OED que, em sua utilização, acabam por descartar muitos dos grupos englobados pelo Atendimento Especial Especializado (AEE). Com base nisso, todos os OED foram avaliados em zero estrela. Quanto à Reutilização, todos os OED podem ser aplicados, não importando a origem dos alunos, e nenhum se relaciona com algo específico do cotidiano de uma região. Sendo assim, os OED receberam 5 estrelas.

\section{Considerações Finais}

Pela análise realizada é possível concluir que os OED trazem propostas de exploração de conteúdos matemáticos a partir do envolvimento do aluno, que interage com o OED efetivamente. Alguns deles demandam que o professor tenha desenvolvido o conteúdo previamente, enquanto outros possibilitam que o professor utilize o OED para introduzir o conceito. São propostas diferentes, ambas relevantes no processo de aprendizagem dos alunos. O papel do professor é fundamental para identificar sua mediação em cada tipo de OED.

Como aspectos de melhoria dos OED indicamos a integração aos livros didáticos, de modo que não apareçam apenas como uma "etiqueta" no livro, mas que sua relação com o conteúdo em estudo esteja claramente apresentada, tanto no livro do aluno, como do professor, onde também deveria conter orientações de uso. Outro aspecto relevante a considerar na melhoria dos OED é a falta de acessibilidade que os objetos apresentam aos alunos do AEE. Considerando que a Lei 13.146/2015 prevê a inclusão dos alunos com deficiência, os OED poderiam oferecer ferramentas para que este grupo de alunos possa explorar os OED. Por fim, observamos que outro aspecto que deixou a desejar refere-se ao feedback por parte dos usuários. Um canal de interação com os alunos e/ou professores poderia contribuir para a melhoria contínua dos OED, pois é na prática da utilização dos recursos que aparecem sugestões reais de melhoria. 


\section{Agradecimentos}

Agradecemos ao GPIMEM - Grupo de Pesquisa em Informática, outras Mídias e Educação Matemática, pela leitura cuidadosa e contribuições para melhoria do texto.

Também agradecemos à FAPEP, pelo apoio financeiro à pesquisa que originou o presente artigo (Processo 2013/22795-3).

\section{Referências}

AMARAL, Rúbia B. Textbook and technology: an analysis of multimedia learning in Brazil In: International Conference on Mathematics Textbook Research and Development (ICMT), 2014, Southampton, Proceeding of ICMT, 2014. v.1, p.1-7.

. The experience of Brazil in integrating technology in textbooks: a multimedia learning analysis. In: 40th Annual Conference of the International Group for the Psychology of Mathematics Education, 2016, Szeged, Hungria. Proceedings of 40th PME, 2016. v.1, p.280.

AMARAL-SCHIO, Rúbia B.; RIBEIRO, Carlos M.S. Objetos Educacionais Digitais em uma Coleção de Livros Didáticos de Matemática. In: SCHEFFER, N.F.; HEINECK, A.; COMACHIO, E. Tecnologias da informação e Comunicação na Educação Matemática: articulação entre pesquisas, objetos de aprendizagem e representações. CRV, 2018.

AMARAL, Rúbia B.; RIBEIRO, Carlos M.S.; GODOY, Juliana S. Choosing textbooks without looking at the textbooks? the role of the other's interpretations. In: International Conference on Mathematics Textbook Research and Development, 2014, Southampton. Proceedings of ICMT, 2014, p.1-7.

ARANHA, Sonia. Respondendo Dúvidas sobre Educação. 6 de maio de 2015. Disponível em: < http://www.soniaranha.com.br/o-que-e-atendimento-educacional-especializadoaee/>. Acesso em 10 de novembro de 2017.

BOGDAN, Robert C.; BIKLEN, Sari K. Investigação qualitativa em educação. Porto: Porto Editora, 1994.

BRASIL. Guia de Livros didáticos: PNLD 2014 - Matemática. Brasília: Ministério da Educação, Secretaria de Educação Básica, 2013.

BRASIL. Ministério da Educação. Edital de convocação 06/2011 - CGPLI (PNLD 2014). Brasília, DF, 2012. Disponível em: <http://www.fnde.gov.br/centrais-deconteudos/publicacoes/category/165-editais?download=8046:pnld-2014-editalconsolidado-3-alteracao>. Acesso em: 20 de maio de 2017. 
CANITTO, Newton G. A TV 1.5 - A televisão na era digital. 2009. Tese (Doutorado em Ciências da Comunicação) Escola de Comunicação e Artes. Universidade de São Paulo. 2009.

DENZIN, Norman K.; LINCOLN, Yvonna S. The discipline and practice of qualitative research, In: DENZIN, N.; LINCOLN, Y.S. Handbook of qualitative research. Second edition. Londres: Sage publications, 2000.

FERREIRA, Bruna M.M.; POLETTI, Letícia F.; SANTANA, Kátia P.X. Livros didáticos e os objetos educacionais digitais. In: II Fórum GT 6 - SBEM, Rio de Janeiro. Anais... 2014.

GADANIDIS, George; BORBA, Marcelo C. Our Lives as Performance Mathematicians. For the Learning of Mathematics, v. 28, p. 44-51, 2008.

GUTZLAF, Tais F.; SANTOS, Lázara R.G.; DECO, Ana S. Objetos educacionais digitais: uma análise da visão dos alunos. In: II Fórum GT 6 - SBEM, Rio de Janeiro. Anais... 2014.

LÉVY, Pierre. Cibercultura. Editora 34, São Paulo, 1999, 3ª Edição, p. 81-85.

MAYER, Richard E. Multimedia learning.New York: Cambridge University Press, 2009.

MELITO, Amanda; GOLDINHO, Bruna; AMARAL, Rúbia B. O livro didático de Matemática e seus objetos educacionais digitais. In: II Fórum GT 6 - SBEM, Rio de Janeiro. Anais... 2014.

MOURA, Larissa; AMARAL, Rúbia B. Uma análise inicial dos objetos educacionais digitais presentes em duas coleções aprovadas pelo PNLD. In: II Fórum GT 6 - SBEM, Rio de Janeiro. Anais... 2014.

NESBIT, John C.; BELFER, Karen; LEACOCK, Tracey. Learning Object Review Instrument. - User Manual LORI 1.5. 2004. Disponível em:

<http://www.transplantedgoose.net/gradstudies/educ892/LORI1.5.pdf>. Acesso em: 9 de setembro de 2017.

RIBEIRO, Carlos M; AMARAL, Rúbia B. Guia e tecnologia dos/nos livros didáticos de Matemática: uma primeira discussão. Educação Matemática em Revista. v.51, 2016.

SANTOS, Marcio E. K. L.; AMARAL; Luiz H. Avaliação de Objetos Virtuais de Aprendizagem no Ensino de Matemática. REnCiMa, v. 3, n. 2, p. 83-93, jul/dez 2012.

SOUZA, Joamir R.; PATARO; Patrícia R.M. Vontade de saber. 2.Ed. FTD, 2012.

SKOVSMOSE, Ole. Landscape of Investigation. Zentralblatt für Didaktik der Mathematik, v. 33, Edição 4, p. 123-132, 2011.

VIDICH, Arthur J.; LYMAN, Stanford M. Qualitative Methods: Their History in Sociology and Anthropology. In: DENZIN, N.K.; LINCOLN, I.S. (Org.). Handbook of Qualitative Research. 2.ed. London: Sage publications, 2000. 